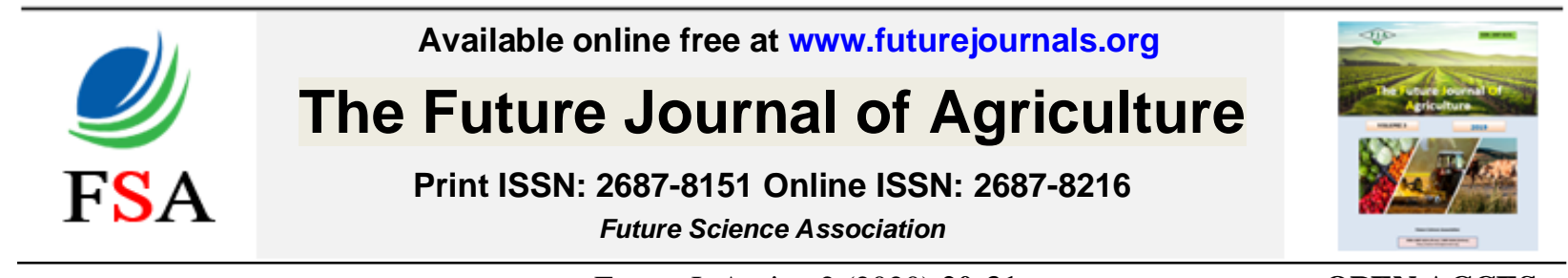

Future J. Agric., 2 (2020) 20-31

OPEN ACCES

DOI: 10.37229/fsa.fja.2020.04.07

\title{
EFFECT OF FULZYME FERTILIZER, RICE RESIDUES AND DAP ON AVAILABLE OF SOME NUTRIENTS FOR THE SOIL OF BUDDED APRICOT SEEDLINGS PRUNUS ARMENIACA L. CV. "ZAGHINIA"
}

\author{
Ayad T. M. Shayal Alalam ${ }^{1}$; Nameer N. Fadhil ${ }^{1}$ and Mothafer A. Dawood ${ }^{2}$ \\ ${ }^{1}$ Hort. \& Landscape Design Dept., College of Agric. \& Forestry, Mosul Univ., Iraq. \\ ${ }^{2}$ Soil Sci. \& Water Resources Dept., College of Agric. \& forestry, Mosul Univ., Iraq.
}

*Corresponding author: Ayadtariq75@yahoo.com Received: 8 Mar. 2020 ; Accepted: 7 Apr. 2020

\begin{abstract}
The study was conducted in the nursery of Hort. Dept., College of Agriculture and Forestry, Mosul University, Iraq, during 2018 season to study the response of budded "Zaghinia" apricot on seedlings rootstock to bio, organic and chemical fertilizers, and their effects on seedling growth. The studied factors were as follows: Bio fertilizer Fulzyme $\left(0,1\right.$ and $2 \mathrm{~g}$. seedling $\left.{ }^{-1}\right)$, organic fertilizer (Rice residue) $(0,1 \mathrm{and} 2 \mathrm{~kg}$. seedling $\left.^{-1}\right)$ and DAP fertilizers $\left(0,5\right.$ and $10 \mathrm{~g}$. seedling $\left.{ }^{-1}\right)$. The study was performed by using split-split plots within factorial experiment in randomized complete block design (RCBD), with 3 factors and 3 replicates, by using 6 seedlings for each treatment. Treatment means were compared by using Duncan multiple levels at $5 \% \mathrm{p}$. the most important results obtained were as follows: 1 and 2 gm.seedling $^{-1}$ of bio fertilizer (Fulzyme) and

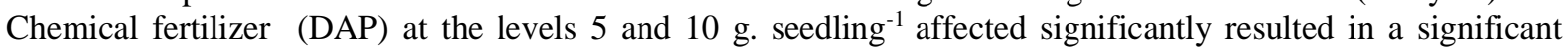
increase in soil available nitrogen, while the addition of organic fertilizer (rice residues) and for both levels 1 and $2 \mathrm{~kg}$. Seedling-1 gave a significant increase in nitrogen, phosphorus, ready-made potassium and $\mathrm{pH}$ of the seedling soil, and the bilateral interaction had a significant role in the growth of seedlings, especially the treatment of the interaction between the fertilizer (Fulzym) and organic fertilizer (Rice residues), which have a significant effect in giving the best results in available nitrogen, phosphorus and potassium in the soil, and the triple interference also gave a significant increase in all studied traits.
\end{abstract}

Key words: Apricot, Fulzyme, rice residue, DAP, fertilization, available nutrients in soil.

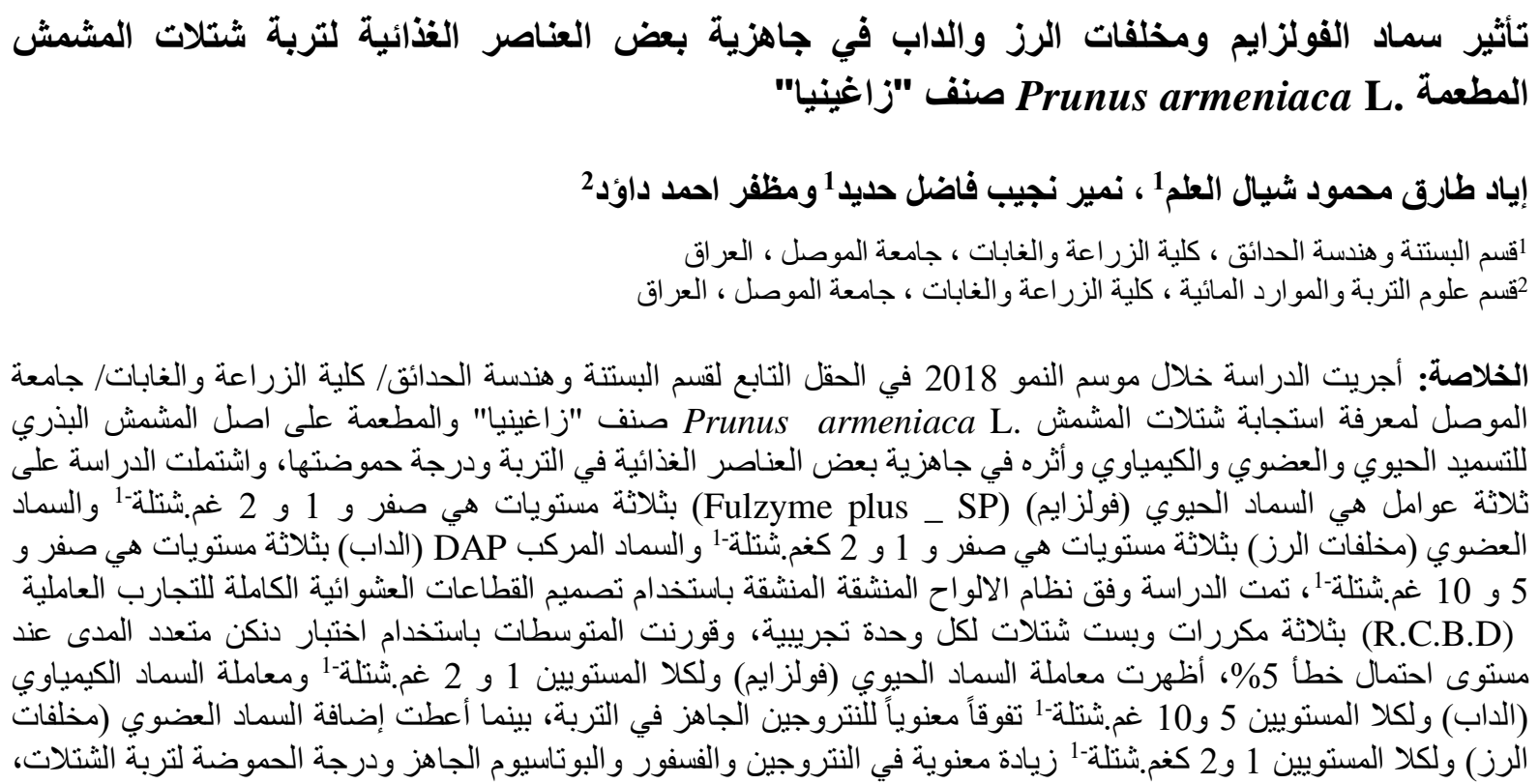




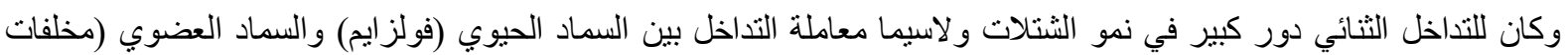

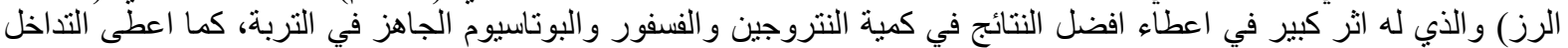

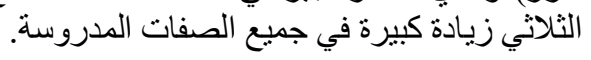

الكلمات الدالة: المشمش، فولزايم، مخلفات الرز، الداب، التسميد، المغذيات الميسرة في التربة.

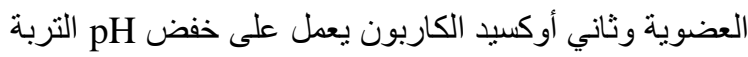

المقدمة

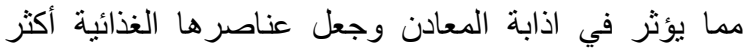

جاهزية.

من الأسمدة المستخدمة حديثاً السماد الحيوي فولزايم

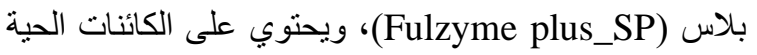

الدقيقة وهي نوعين من البكتريا النافعة Bacillus subtillis

Pseudomonas putidag

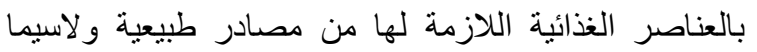
عنصر الفسفور مما يقلل الاعتماد على الأسمدة الكيميائية الكختلفة الأمر الذي يؤدي إلى التقليل من تلوث الإن البيئة وتقليل الإنيل

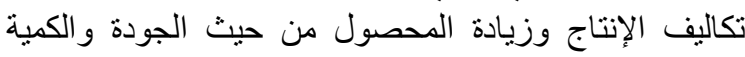
(Scialabba)

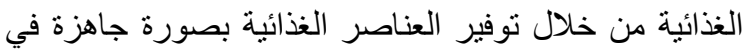
التربة المزروعة فيها بحيث يمكن لجذور الثنتلات الثنات امنصاصها

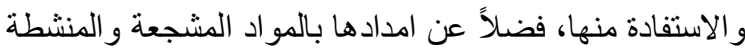

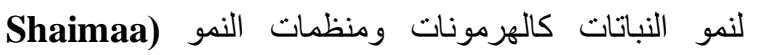
والربة Massoud، 2017)، وتعمل على زيادة المادة العضوية في

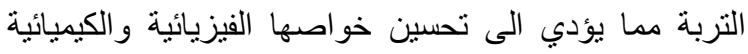

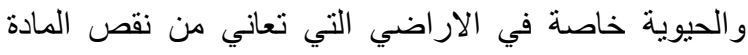
العضوية (الحداد، 2003 والبدوي، 2008).

وللتسميد الكيمبائي دور في تطوير زر اعة الفاكهة، ومنها

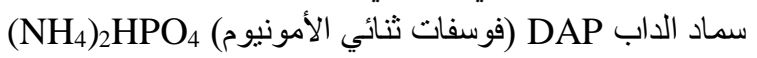

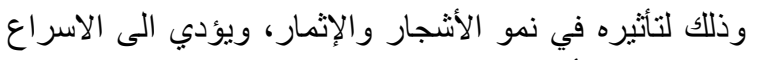

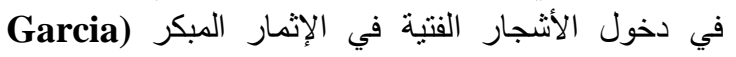

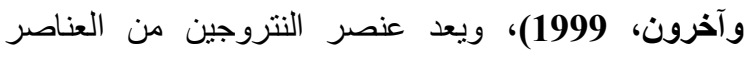

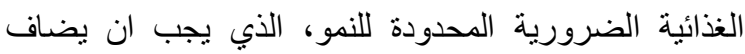

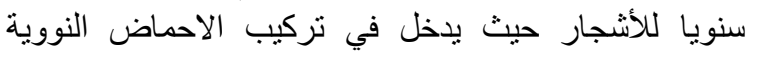
و البروتينات وجزيء الكلوروفيل وكنللك في تركيب الإني الانزيمات

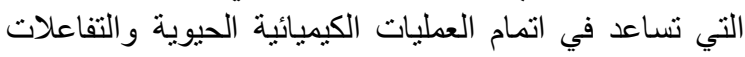

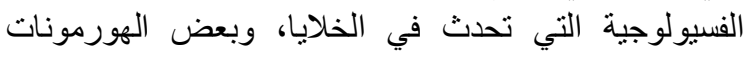

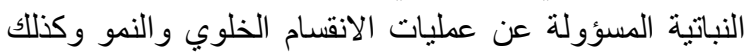

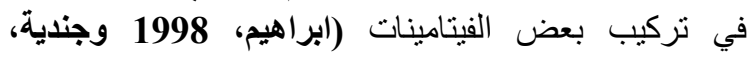

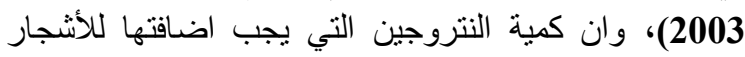

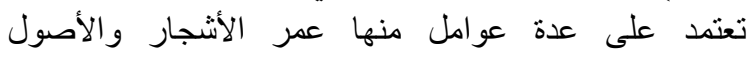

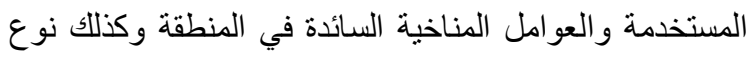

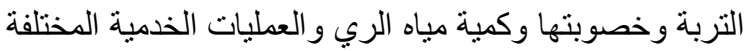

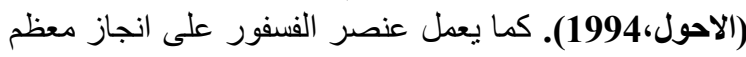

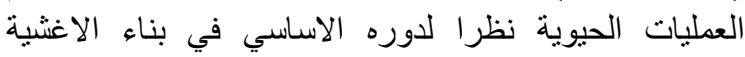

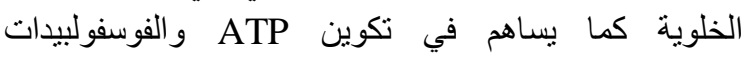

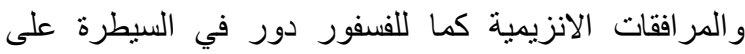
تفاعلات البناء الضوئي و التنفس وزيادة عدد الجذور (النعيمي،

(1984 ومحمد،1985).

يعود المشمش (Prunus armeniaca L.) apricot للعائلة الوردية Rosaceae وتحت عائلة اللوزيات (ذات النواة الحجرية) Prunoidae، ويعتبر من أثنجار فاكهة الاكتية

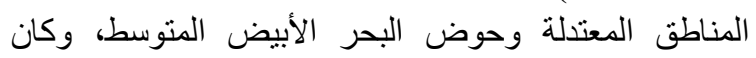

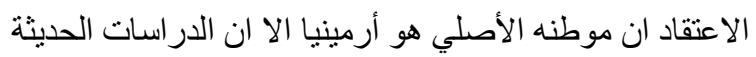

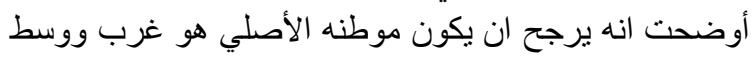

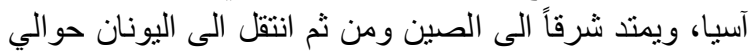

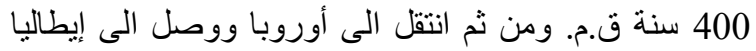

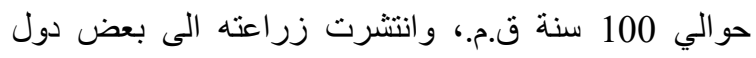

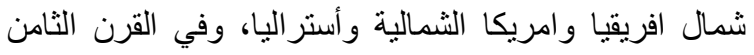

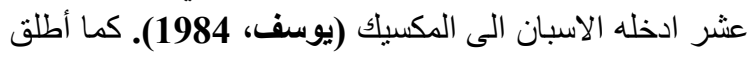

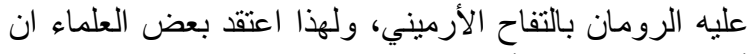

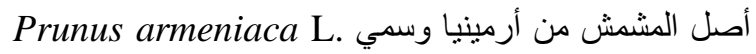

(2007، Punia)

تحتوي الترب في العراق على الكثير من العناصر الغذائية

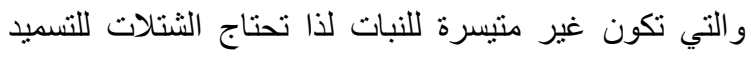

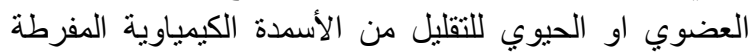

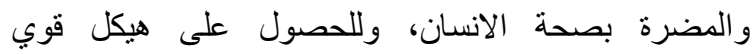

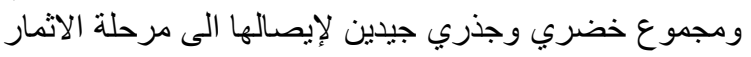

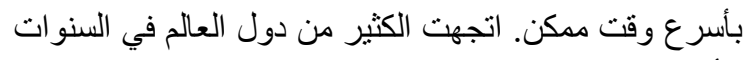

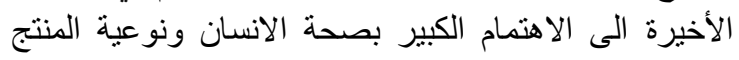

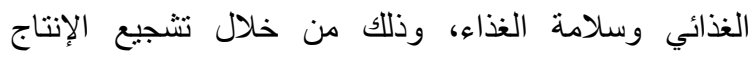
العضوي واستعمال المغذيات ذات الأصل العضوي كلاتل كبديل

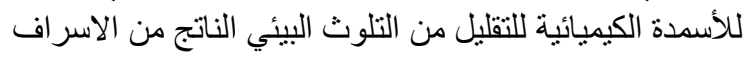

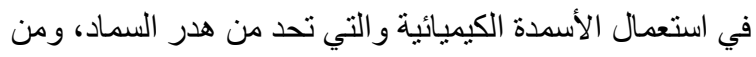

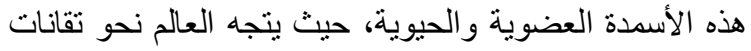

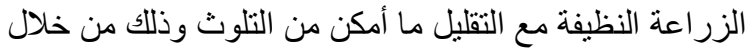

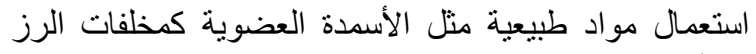

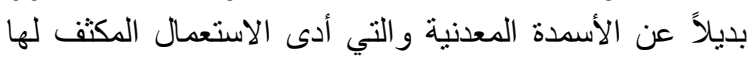

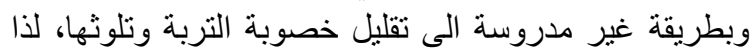

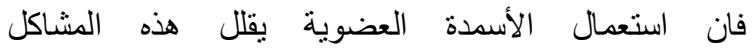
(Zaghloul)

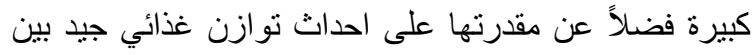

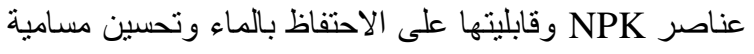

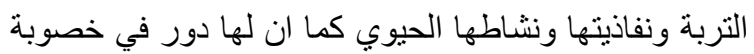

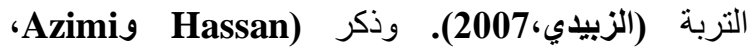
2012) ان الاستعمال الأمثل للأسمدة العضوية يسبب زيلة زيادة

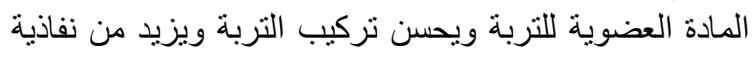

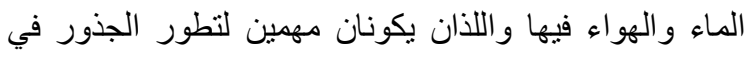

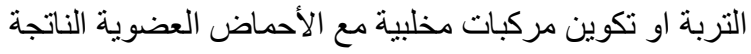

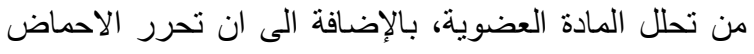


البوتاسيوم الجاهز (ملغم.كغم تربـة-1): قُدر باسـتخدام جهاز قياس العناصر باللهب (Flame Photometer) حسب طريقة

.(1958) Jackson

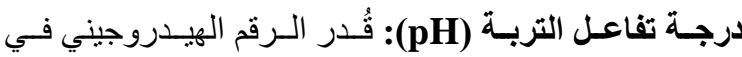

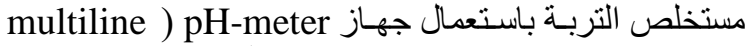

(P4/set-2) وحسب ما ورد في Page و وآخرين (1982).

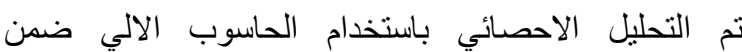

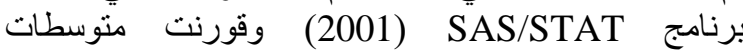
المعاملات باستخدام اختبار دنكن متعدد الحدود عند مستوى

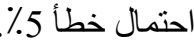

\section{النتائج والمناقشة}

النتروجين الجاهز (ملغم.كفم تربة-1): نظهر النتائج في الثكل

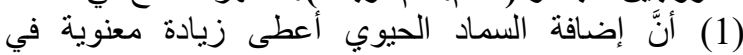

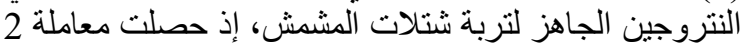

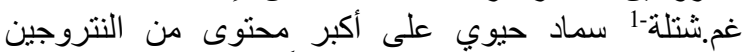

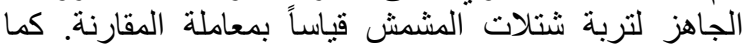

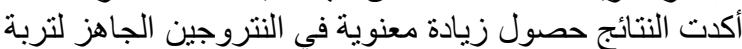

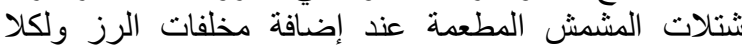

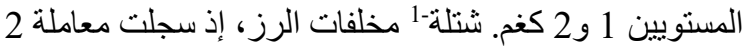
كغ. شتلة-1 مخلفات الرز أعلى محتوى للتربة من النتروجين التئين

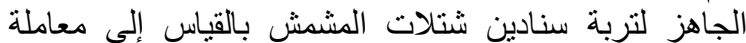

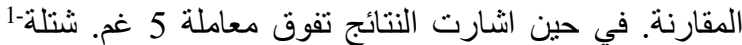
سماد الداب معنوياً بالقياس إلى معاملت فئلة المقارنة في محتوى تربة شتلات المشمش من النتروجين.

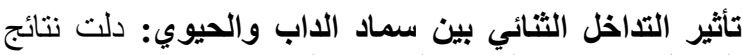

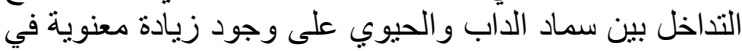

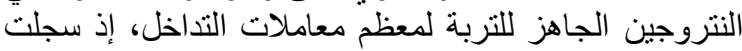

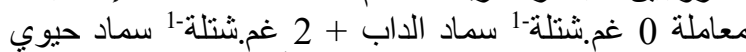

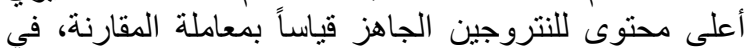

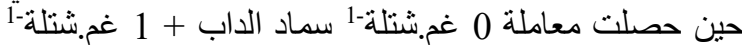
سماد حيوي أقل محتوى من النتروجين الجاهز لتربة شتيلات التهات المشمش المطعمة (الجدول 1).

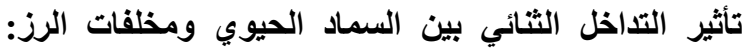
تظهر النتائج تفوق معنوي لمعظم معاملات التداخل، إذ حقة التّات

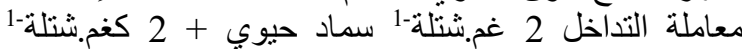

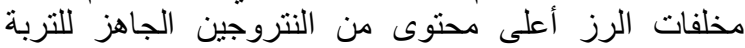

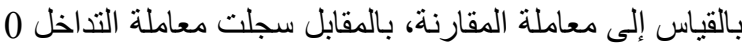

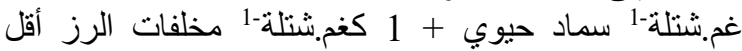

محتوى من النتروجين الجاهز لتربة الثتلات (الجدول 1).

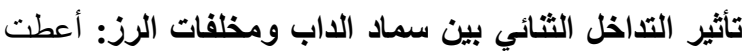

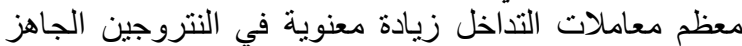

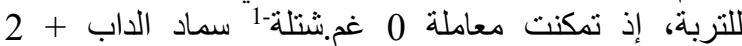

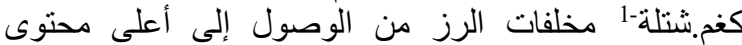

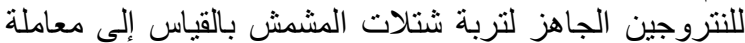

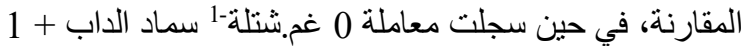
كغ.شتلة-1 مخلفات الرز أقل محتوى للتربة من النتروجين الجاهز (الجدول 1).

تأثير التذاخل الثُلاثي بين السماد الحيوي ومخلفات الرز

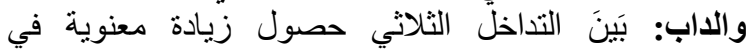
النتروجين الجاهز لتربة شتلات المشمش المطعمة لمعظم

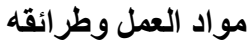

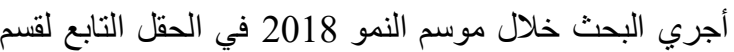

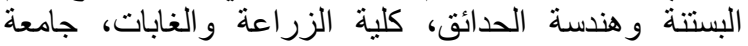

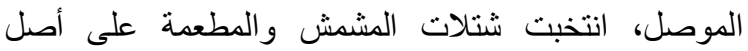
المشمش البذري في الموسم الماضي 2017 (شهر آب) من

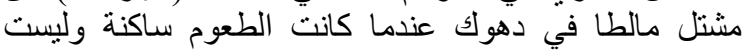

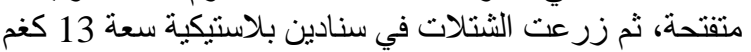
تربة بتاريخ 2018/2/1، وقرطت ونت أعلى منطقة النطعيم بـ 10

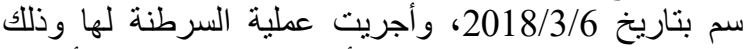
بإزالة جميع النموات الموجودة أسفل منطقة النطعيم و أعلاها ولتها

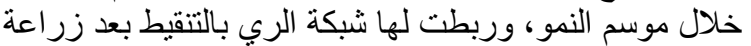

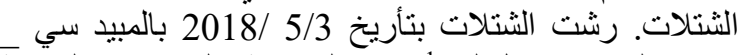

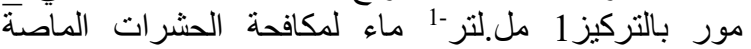

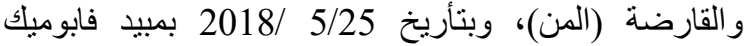

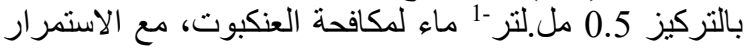

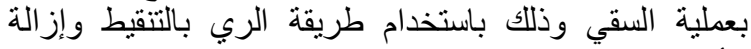
الأدغال من حول الثتلات وكلما دعت الحاجةً. استخدم في تنفيذ التجربة ثلاثة عو امل و هي كما يأتي:

السماد الحيوي فولزايم بلاس (Fulzyme plus _ SP):

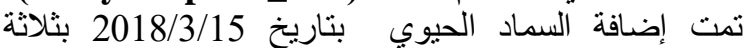

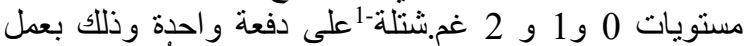

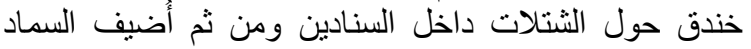

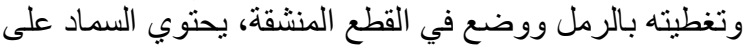

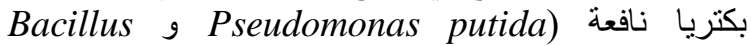
(subtilis

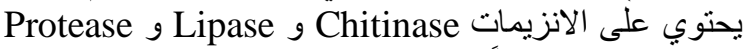
و Amylase فضلاً عن المنشطات البيولوجية كالجبرلينات

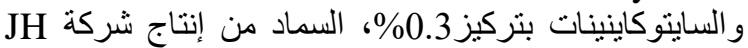
Biotech, Inc السماد العضوي (مخلفات الرز): تم خلط سماد مخلفات الرز

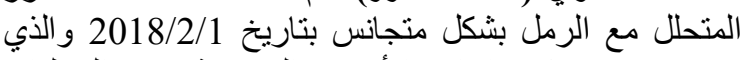

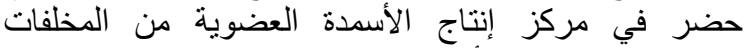

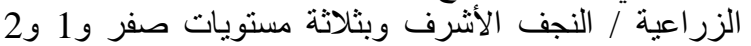

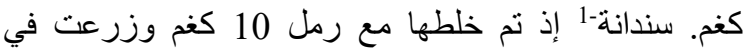
سنادين بلاستيكية سعة 13 كغم ولمرة ولماحة ولدة في الموسم ووضع في القطع المنشقة المنشقة.

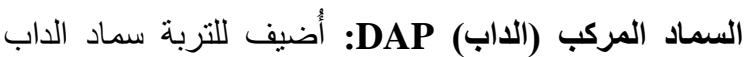
يحتوي (فوسفات ثنائي الأمونيوم) DAP

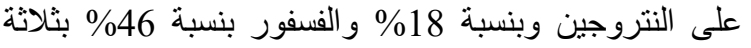

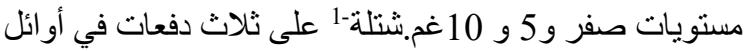

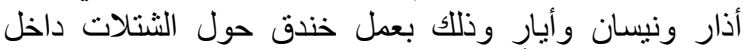

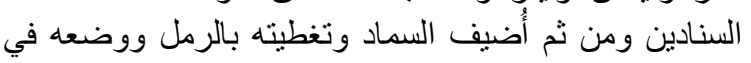
القطع الرئيسة. وعند انتهاء الدراسة أجريت عملية بلية التحليل فيليل الكيمائي لتربة الثنتلات في نهاية الموسم التقدير العناصر الآتية:

النتروجين الجـاهز (ملفم.كفم تربـة-1): تم تقديره باستعمال

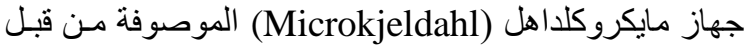
.(1999) Raghupathi و Bhargava

الفسـفور الجـاهز (ملفم.كغم تربـة-1): قُّدر باسـتخدام جهـاز

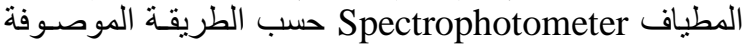
في Page وآخرين (1982). 
معاملة المقارنة، في حين سجلت معاملة 0 غم.شتلة-1 سماد

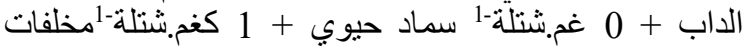
الرز أقل محتوى للتربة من النتروجين الجاهز (الجدول 1 1).
معاملات التداخل، إذ أعطت معاملة 0 غم.شتلة-1 سماد الداب

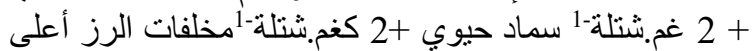
زيادة للنتروجين الجاهز لتربة شتلات المشمش بالقياس إلى الى الى

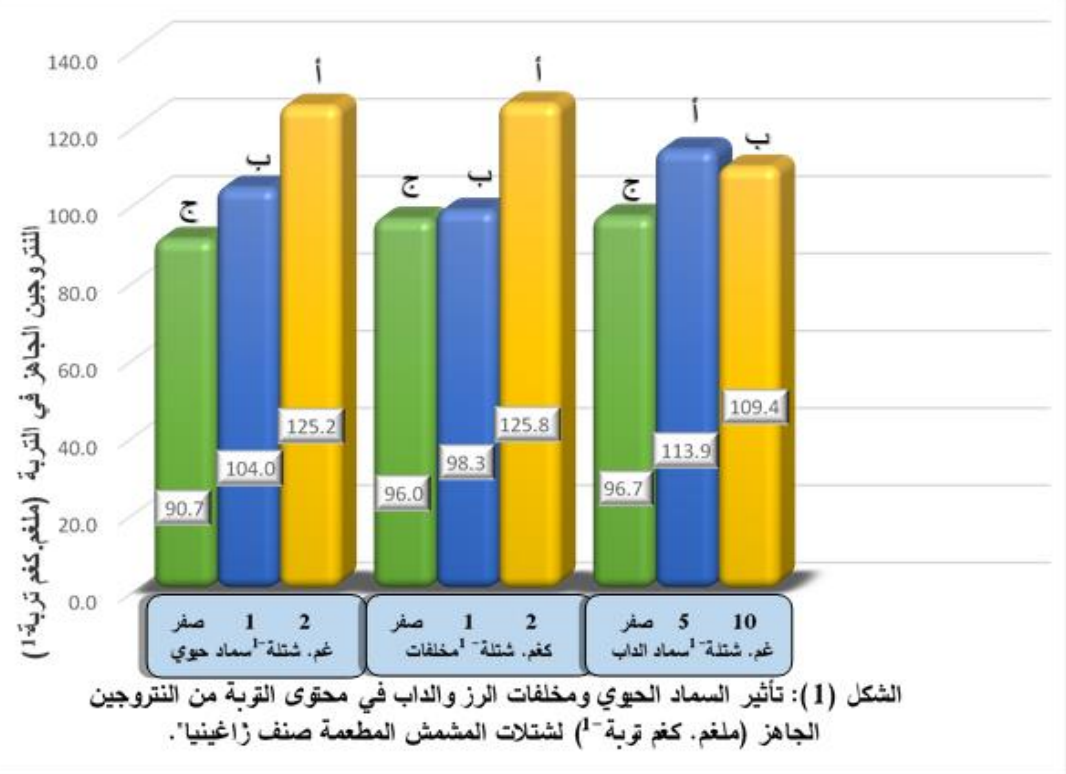

جدول 1. تأثير التاخل الثنائي والثلاثي للسماد الحيوي ومخلفات الرز والداب في النتروجين

الجاهز (ملغم. كفم تربة-1) لتربة شتلات المشمش المطعمة صنف "زاغي الثينيات

\begin{tabular}{|c|c|c|c|c|c|}
\hline \multirow{2}{*}{ السماد الحيوي الداب } & \multicolumn{3}{|c|}{ مخلفات الرز (كفم.شتّلة_1) } & \multirow{2}{*}{ (غم.شتلة-1ان) } & \multirow{2}{*}{ (غمـثاد الدابة) } \\
\hline & 2 & 1 & صفر & & \\
\hline 76.66 و & 99.00 د & j 50.00 & 81.00 و & صفر & \multirow{3}{*}{ صفر } \\
\hline j 66.33 & ز 50.00 & 99.00 د & j 50.00 & 1 & \\
\hline 147.00 & 245.00 & 98.00 ده & 98.00 ده & 2 & \\
\hline .98.00 & 98.00 دـ ـ & 98.00 دـ & 98.00 دـ & صفر & \multirow{3}{*}{5} \\
\hline 113.55 د & ( 97.66 ده & 146.00 ج & .97 .00 & 1 & \\
\hline 130.22 ج & 147.00 ج & 146.66 ج & ه97.00 & 2 & \\
\hline ๑97.55 & ( 98.00 ده & 98.00 دـ & .96 .66 & صفر & \multirow{3}{*}{10} \\
\hline 132.22 ب & 199.00 ب & ز 50.66 & 147.00 ج & 1 & \\
\hline .98.44 & 98.33 ده & 98.00 ده & 99.00 & 2 & \\
\hline & 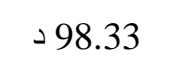 & 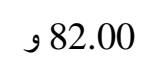 & $\circ 91.88$ & صفر & \multirow{3}{*}{ السماد الحيوي } \\
\hline & 115.55 ب & 98.55 د & 98.00 د & 1 & \\
\hline & 163.44 & 114.22 ج & 98.00 & 2 & \\
\hline & 131.33 & $\circ 82.33$ & 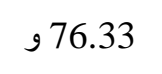 & صفر & \multirow{3}{*}{ سماد الداب } \\
\hline & 114.22 ج & 130.22 ب & 97.33 د & 5 & \\
\hline & . 131.77 & $\circ 82.22$ & 114.22 ج & 10 & \\
\hline
\end{tabular}


تأثير السماد العضوي (مخلقات الرز): أدت اضافة مخلفات الرز إلى تربة شتلات المشمش إلى زيادة معنوية البوتاسيوم

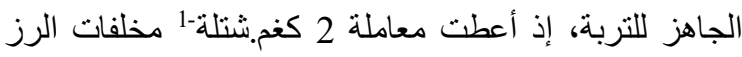

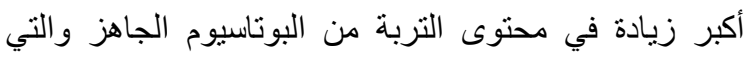
بلغت 104\% بالقياس إلى معاملة المقارنة (الثكل 3). تأثير التداخل الثنائي بين سماد الداب والحيوي: كان للتداخل

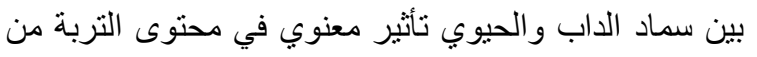

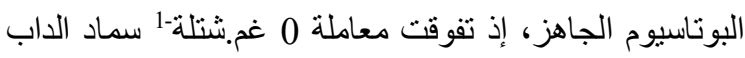

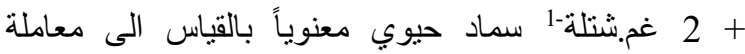

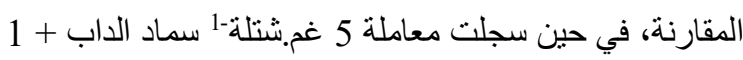
غم.شتلة-1 سماد حيوي أدنى محتوى من البونات مناسيوم الجاهز

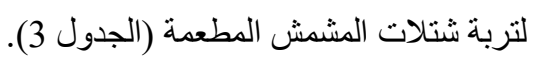
تأثير التاخل الثنائي بين السماد الحيوي ومخلفات الرز:

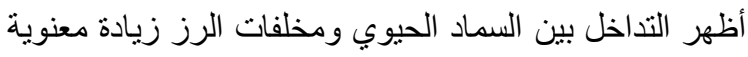
في محتوى التربة من البوتاسيوم الجاهز ، إذ سجل التداخل بين التبادين

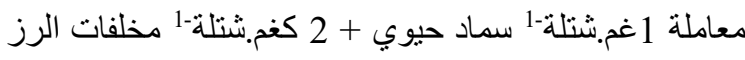
أكبر كمية من البوتاسيوم الجاهز للتربة قياساً بمعاملة المقارنة،

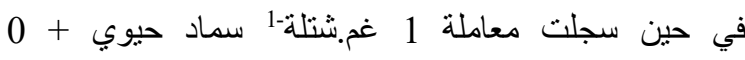
كغم.شتلة-1 مخلفات الرز أقل محتوى من البوتاسيوم الجاهز لتربة شتلات المشمش(الجدول 3).

تأثير التداخل الثنائي بين سماد الاب ومخلفات الرز: أعطى التداخل بين سماد الداب ومخلفات الرز زيادة معنوية في كمية التية البوتاسيوم الجاهز للتربة، إذ حققت معاملة 0 غم.شتلة-1 سماد التهاد الداب + 2 كغ.شتلة-1 مخلفات الرز أكبر كمية من البوتاسيوم

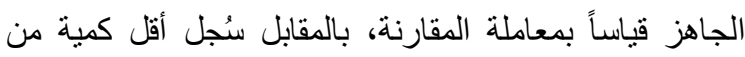

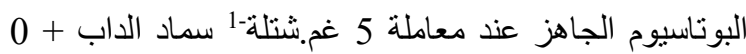

$$
\text { كغ.شتلة-1 مخلفات الرز(الجدول 3) ماهن }
$$

تأثير التذاخل الثلاثي بين السماد الحيوي ومخلقات الرز

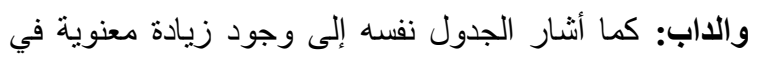
البوتاسيوم الجاهز لتربة الثتلات عند إضافة جميع معاملات

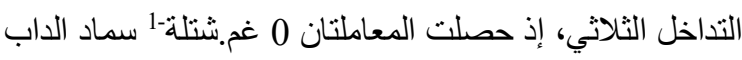

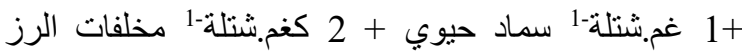

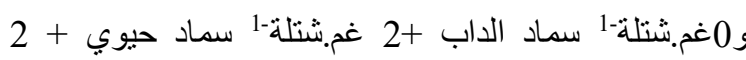
كغ.شتلة-1 مخلفات الرز على أكبر كمية من البوتاسيوم الجاهز

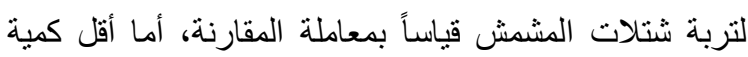

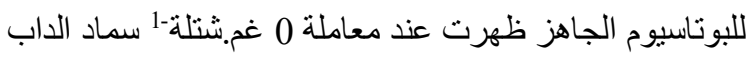

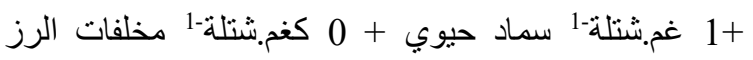

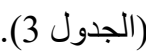

الفسفور الجاهز (ملفم.كفم تربة-1)

تأثير السماد الحيوي (فولزايم) والاب: لم تظهر إضافة

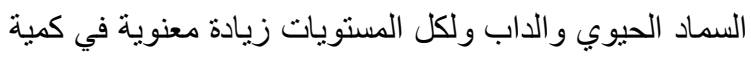
الفسفور الجاهز لتربة سنادين شتلات المشمش المطعمة (الثكل

تأثير السماد العضوي (مخلفات الرز): أظهرت النتائج تفوقاً

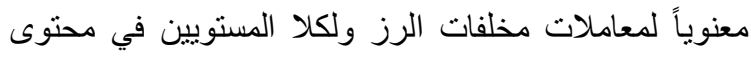

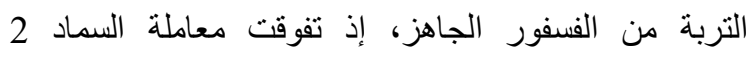
كغ.شتلة-1 مخلفات الرز معنوياً في محتوى التربة من الفسفور الجاهز بالقياس إلى معاملة المقارنة (الثكل 2)

تأثير التاخل الثنائي بين سماد الاب والحيوي: أعطى زئل

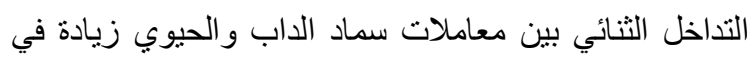

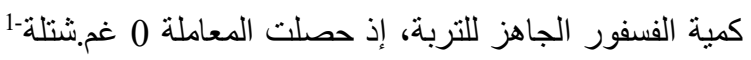

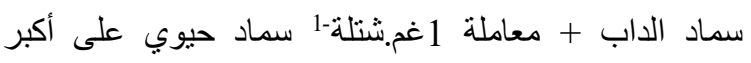
محتوى من الفسفور الجاهز بالقياس إلى معاملة المقارنة

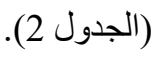

تأثير التداخل الثنائي بين السماد الحيوي ومخلفات الرز:

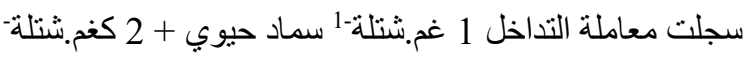
1 مخلفات الرز أكبر زيادة في الفسفور الجاهز لتربة شتئلات

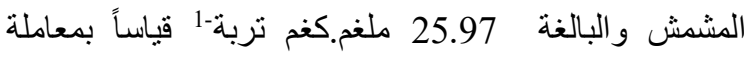
المقارنة البالغة 8.10 ملغم.كغم تربة-1 (الجدول 2) مالغة تأثير التاخل الثنائي بين سماد الداب ومخلفات الرز: أكدت

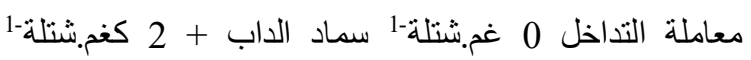
مخلفات الرز وجود اكبر زيادة معنوية في الفسفور الجاهز

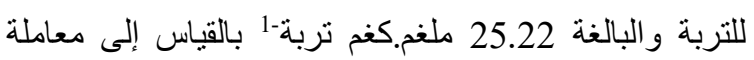

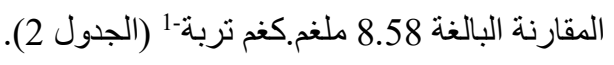
تأثير التداخل الثلاثي بين السماد الحيوي ومخلفات الرز والداب: نلاحظ من الجدول (2) ظهور تفوق معنوي لمعاملة 0

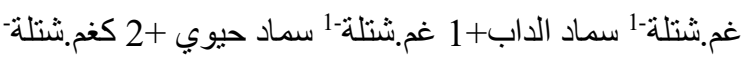

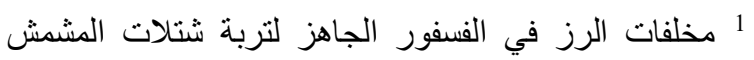
وبزيادةٍ بلغت 753\% قياساً بمعاملة المقارنة.

البوتاسيوم الجاهز (ملفم.كفم تربة-1) تأثير السماد الحيوي (فولزايم) والداب: أظهرت النتائج حصول انخفاض معنوي في محتوى التربة من البوتاسيوم

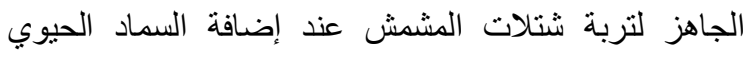

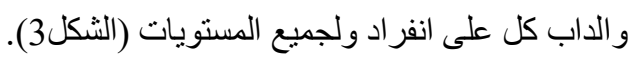




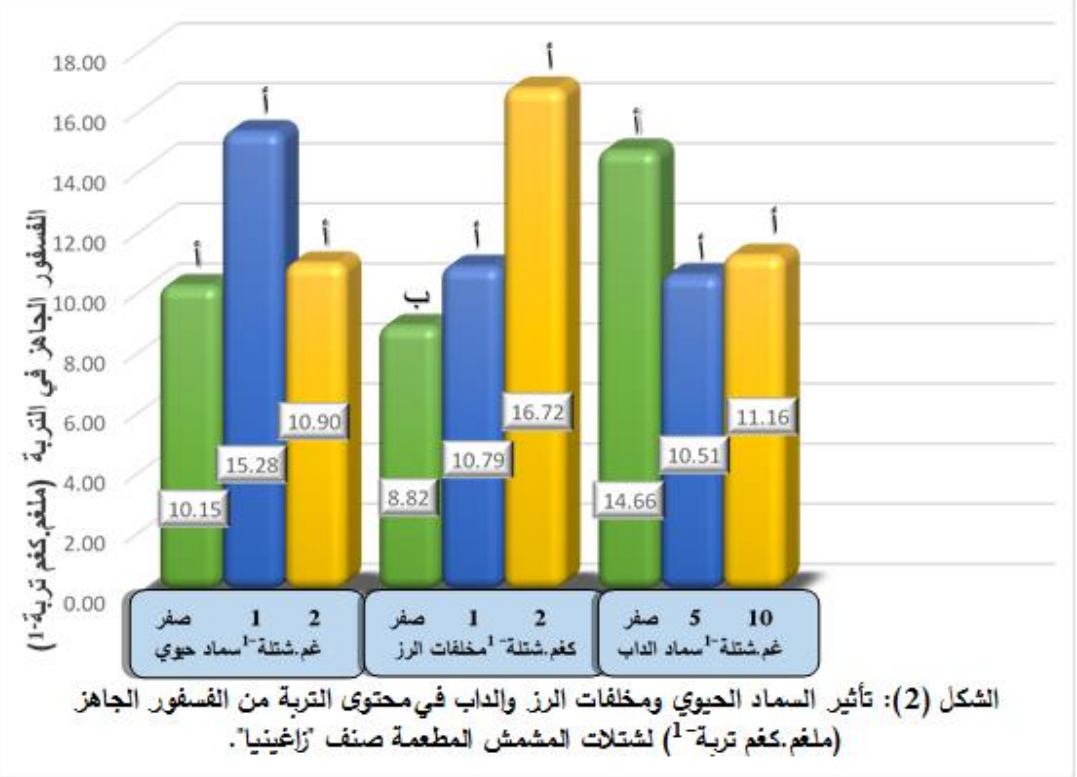

جدول 2. تأثير التذاخل الثنائي والثلاثي للسماد الحيوي ومخلفات الرز والداب في الفسفور الجاهز

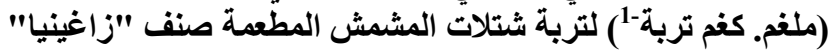

\begin{tabular}{|c|c|c|c|c|c|}
\hline \multirow{2}{*}{ 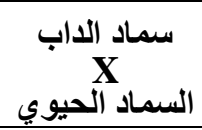 } & \multicolumn{3}{|c|}{ مخلقات الرز (كغف.شتلة-1') } & \multirow{2}{*}{ (غم.شتلة_+1اديوي } & \multirow{2}{*}{ (غم.شتلة__اب ) } \\
\hline & 2 & 1 & صفر & & \\
\hline 8.20 & 9.10 ب & 9.20 ب. & 6.30 & صفر & \multirow{3}{*}{ صفر } \\
\hline 24.24 & 53.73 & 10.50 & 8.50 & 1 & \\
\hline 11.54 أب & 12.83 & 10.83 & 10.97 ب & 2 & \\
\hline 11.40 أب & 12.90 ب & 11.83 ب & 9.47 ب & صفر & \multirow{3}{*}{5} \\
\hline 10.25 أب & 12.60 & 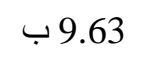 & 8.53 & 1 & \\
\hline و 9.88 أب & 11.43 & 10.70 & 7.53 & 2 & \\
\hline 10.87 أب & 13.50 & 10.60 & 8.53 & صفر & \multirow{3}{*}{10} \\
\hline 11.34 أب & 11.60 & 12.80 & 9.63 & 1 & \\
\hline 11.26 أب & 12.80 & 11.03 & 9.97 & 2 & \\
\hline & 11.83 & 10.54 ب & 8.10 & صفر & \multirow{3}{*}{ السماد الحيوي } \\
\hline & 25.97 & 10.97 ب & 8.88 & $\mathbf{1}$ & \\
\hline & 12.35 ب & 10.85 & 9.48 ب. & 2 & \\
\hline & 25.22 & 10.17 ب & ا & صفر & \multirow{3}{*}{ سماد الداب } \\
\hline & 12.31 أب & 10.72 ب & 8.51 & 5 & \\
\hline & 12.63 أب & 11.47 أب & و & 10 & \\
\hline
\end{tabular}




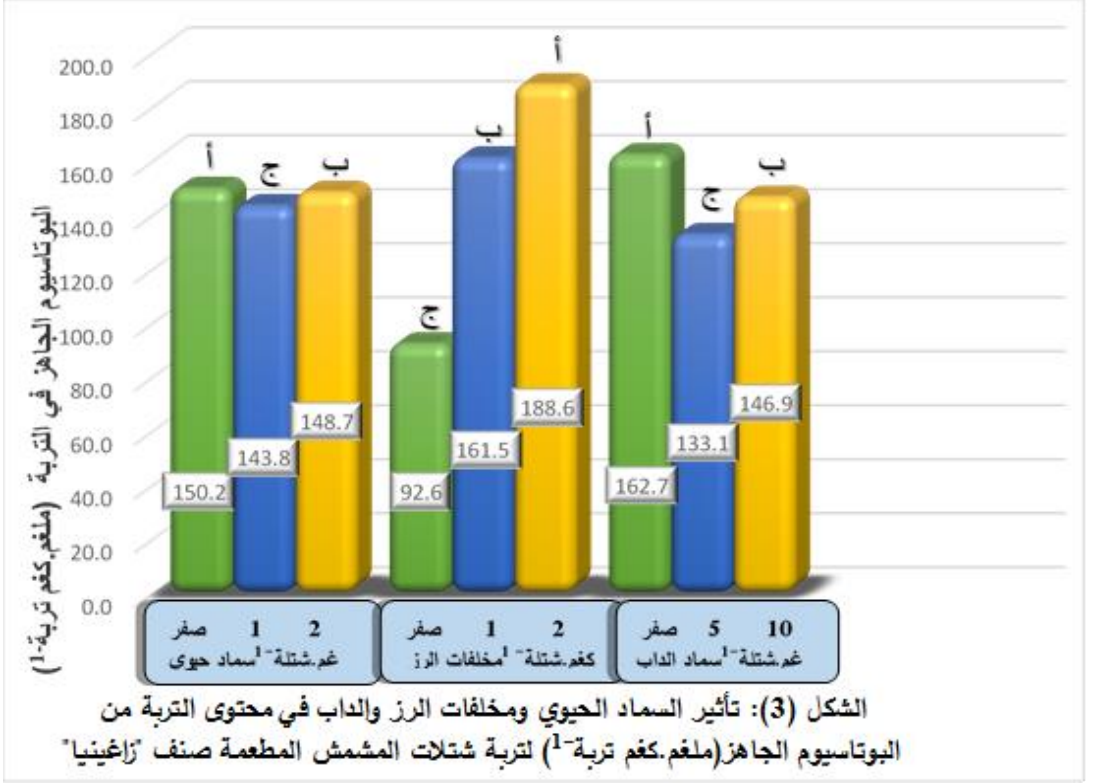

\begin{tabular}{|c|c|c|c|c|c|}
\hline \multirow{2}{*}{ سماد الداب السماد الحيوي } & \multicolumn{3}{|c|}{ مخلفات الرز (كفم.شتلة_1) } & \multirow{2}{*}{ (غلم.شتلة_-1ابوي } & \multirow{2}{*}{ سماد الداب } \\
\hline & 2 & 1 & صفر & & \\
\hline 152.88 ج & 181.00 ج & 201.00 & 76.66 ك 76. & صفر & \multirow{3}{*}{ صفر } \\
\hline 161.00 ب & 241.00 & . 161.00 & ال & 1 & \\
\hline 174.33 & 241.00 & .161 .00 & j 121.00 & 2 & \\
\hline . 148.33 & 182.33 ج & 161.66 دـه & ح101.00 & صفر & \multirow{3}{*}{5} \\
\hline ح 108.88 & 142.33 و & ح 102.00 & 82.33 ط ي & 1 & \\
\hline و 142.11 & 162.00 دـ & 181.33 ج & 83.00 طـي & 2 & \\
\hline 149.55 د & 183.33 ج & 181.00 ج & ا 84.33 & صفر & \multirow{3}{*}{10} \\
\hline 161.55 ب & 201.00 & 182.33 ج & ح 101.33 & 1 & \\
\hline j 129.77 & 163.66 د & j 122.66 & 103.00 & 2 & \\
\hline & 182.22 ج & 181.22 ج & ز 87.33 & صفر & \multirow{3}{*}{ مخلفات الرز } \\
\hline & 194.77 & $\circ 148.44$ & j 88.22 & 1 & \\
\hline & 188.88 ب & 155.00 & 102.33 & 2 & \\
\hline & 221.00 & 174.33 ج & j92.88 & صفر & \multirow{3}{*}{ سماد الداب } \\
\hline & 162.22 د & • 148.33 & ح 88.77 & 5 & \\
\hline & 182.66 ب & 162.00 & و 96.22 & 10 & \\
\hline
\end{tabular}


تأثير التذاخل الثنائي بين سماد الداب والحيوي: ظهرت فروق

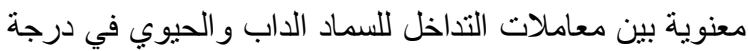
تفاعل التربة (الجدول 4)، إذ سجلت معاملة التداخل 5

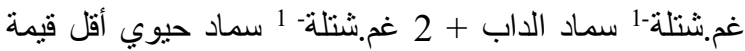

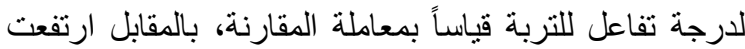
درجة تفاعل التربة إلى أعلى قيمة لها عند التهاعل معاملة التداخل 10 غم.شتلة-1 سماد الداب + 2 غم.شتلة- 1 سماد حيوي.

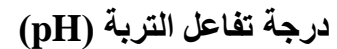

تأثير السماد الحيوي(فولزايم) والداب: لم تظهر أي فروق

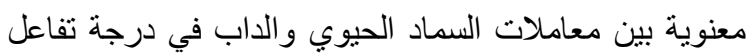
التربة لنتلات المشمش المطعمة صنف "زاغينيا" (الثكل 4). تأثير السماد العضوي (مخلفات الرز): أظهرت إضافة مخلفات

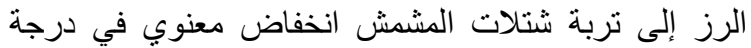

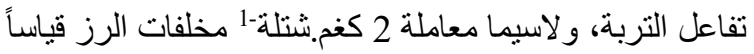
بمعاملة المقارنة (الثكل 4).

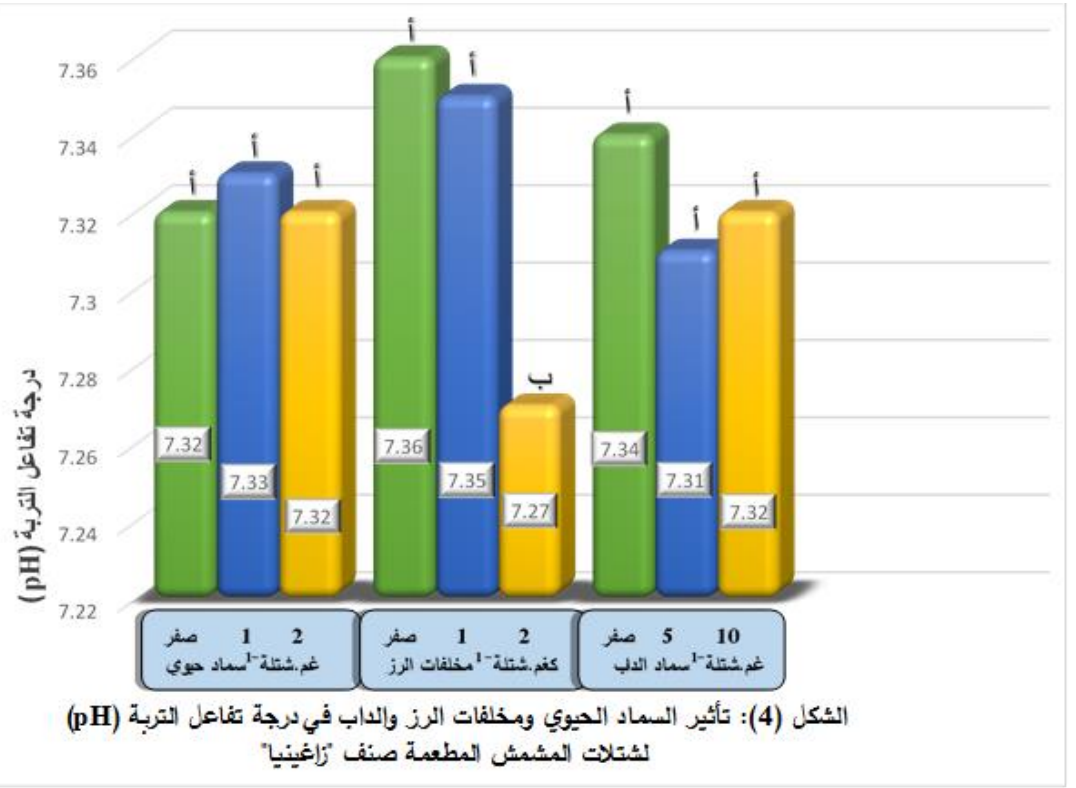

يلاحظ من النتائج أنَّ إضافة السماد الحيوي (فولزايم)

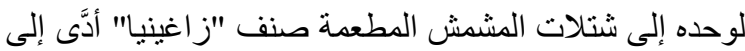
1 حصول تفوق معنوي في النتروجين الجاهز في التربة (الثكل 1), إذ اكد El-Komy (2005) على أنَّنَ فعالية انزيم النتروجينيز اعلى ما يكون عند التلقيح المزدوج بالبكتريا

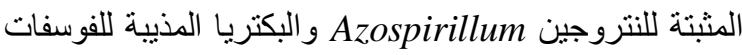
Bacillus polymyxa وآخرون Esitken 142Bacillus OSU الأشجار المشمش صنف "Hacihaliloglu" Biogein بالرمان صنف "Arabi" بالسماد الحيوي

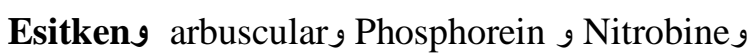
وآخرون(2006) عند التسميد الحيوي بنوعين من بكتريا على (8-Pseudomonas BAg 142 Bacillus OSU) أثجار الكرز الحلو. وقد يعود السبب إلى دور البكتريا في علي خفض الأس الهيدروجيني للتربة وزيادة جاهزية النتروجين الكين فيه وقد أعطى السماد الحيوي(فولزايم) زيادة في محتوى لئري التربة من النتروجين الجاهز (الثكل 19) وذلك لدور بكتريا Pseudomonas putida Bacillus subtilis
تأثير التداخل الثنائي بين السماد الحيوي ومخلفات الرز: أدَّى

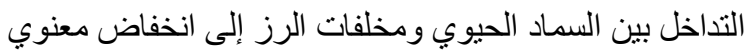
في درجة تفاعل تربة شتلات المشمش المطعمة، إذ سجلت المئل

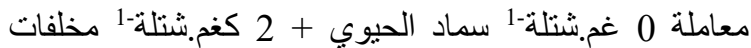
الرز انخفاض معنوي في درجة تفاعل التربة بالقياس الى الى

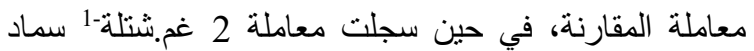
الحيوي+ 0 كغ.شتلة-1 مخلفات الرز أكبر قيمة لدرجة تفاعل التربة (الجدول 4).

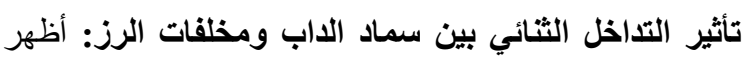

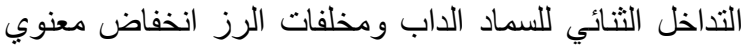

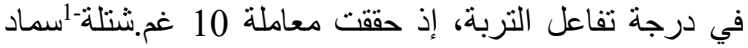
الداب +2 كغ.شتلة-1 مخلفات الرز أكبر انخفاض في دئة درجة تفاعل التربة قياساً بمعاملة المقارنة (الجدول 4). تأثير التداخل الثلاثي بين السماد الحيوي ومخلفات الرز والاب: أظهر التداخل الثثلاثي انخفاض معنوي في درجة تفاعل التربة لشتلات المشمش، إذ سجلت معاملة 10 غ.ش.شتلة-1 فئل

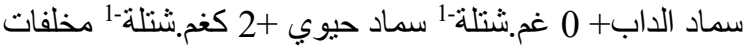
الرز أقل قيمة لدرجة تفاعل للتربة بالقياس إلى معاملة المقارنة

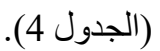


الأحماض العضوية ولاسيما حامضي الفولفيك و الهيوميك

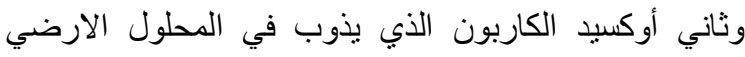

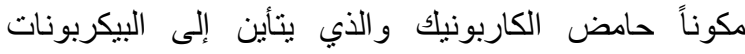

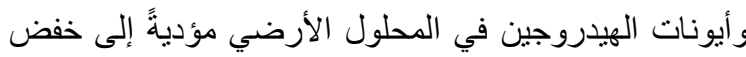

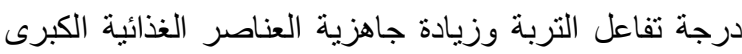

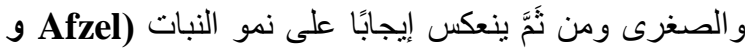
Adams، 1992 وBarakat وآخرون، 2012)، تثابهت النتائج مع ما وجده Sahain وآخرون (2007) واخرن، علد أنثجار التفاح صنف"Anna" والمطعمة على أصل 106

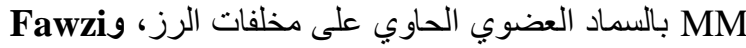
واخرون (2010) عند استخدام الأسمدة العضوية على أثنجار

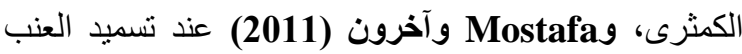

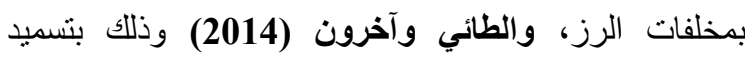
شتلات النارنج بمستخلص مخلفات الرز، والعزان والعباسي و الزهيري

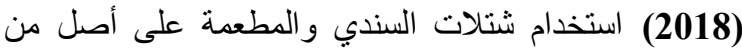

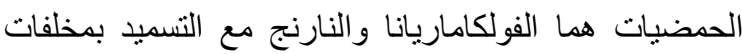

كما أدَّى التسميد بالسماد الكيمياوي المركب الداب

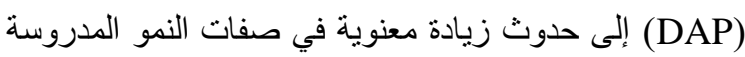

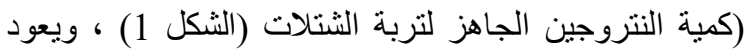

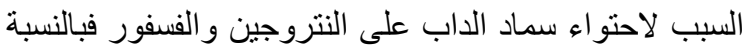

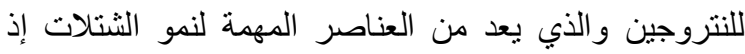

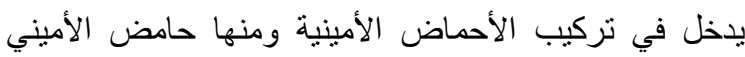
التربنوفان Tryptophan والذي يعد البادئ الاساس لإنتاج

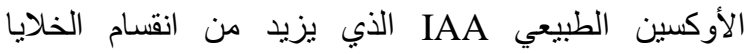

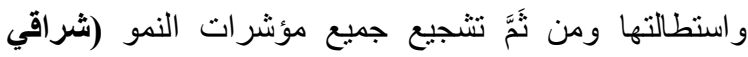

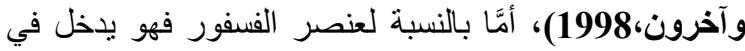

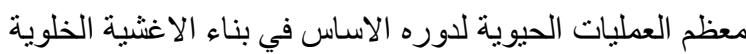

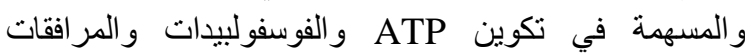

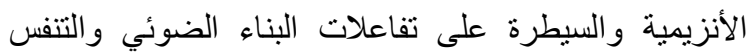
وزيادة عدد الجذور الماصة (النعيمي، 1984 ومحمداء

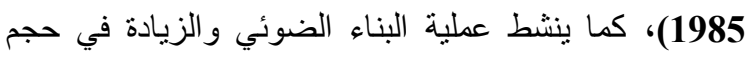

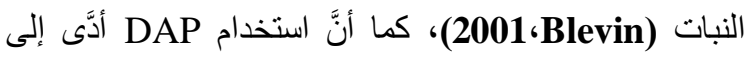

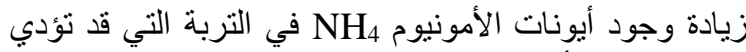

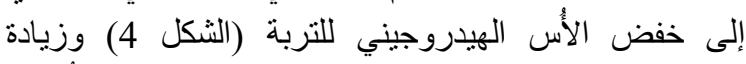

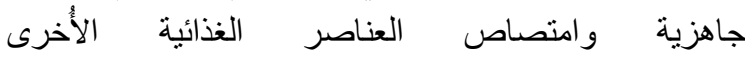

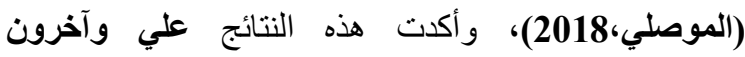
(2012) في تسميد شتلات الزيتون بسماد الداب، والعكام وآخرون (2016) عند إضافة سماد الداب للعنب صنف

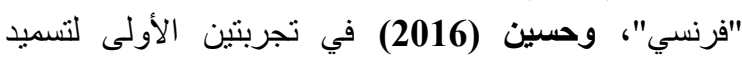
شتلات المشم البذرية بعمر شهرين بسماد الداب ثنائي الأي فوسفات الأمونيوم DAP و الثانية بعمر سنتين.
المواد العضوية المعقدة في التربة وتحويلها إلى أيونات غير عضوية (معدنية) كالأمونيا و النترات بعطلية معدنة النحات النتروجين Nitrogen mineralization يعزى السبب إلى قدرة بكتريا Bacillus على معدنة المركبات العضوية من خلال إنتاجها للأنزيمات مثل مثل أنزيم النائ Phosphodiesterases و Phosphoesterases

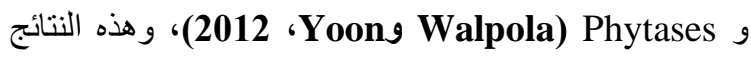
تتفق مع Mario واخرين (2006) Siddiqui (2002) وShekhar واخرين (2006) المتضمنة أنَّ أقصى فائدة من استخدام اللقاح البكتيري يمكن أنْ تحصل مع استعمال لقاح مختلط وتوفير ظروف نجاح نثاط اللقاح في بيئة النبات النياح

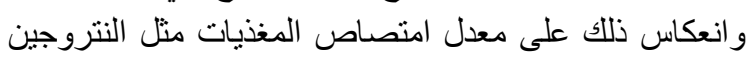

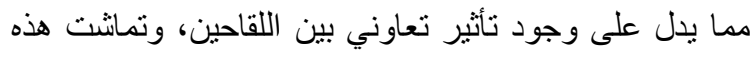

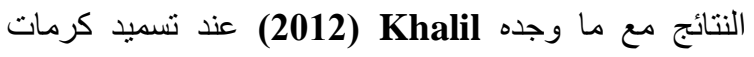
العنب صنف "Flame seedless" بالسماد وجن الحيوي (Nitrobine + Phosphorein + phosphorein) الدين وبركات (2016) وذللك بإضافة السماد الحيوي الحاوي

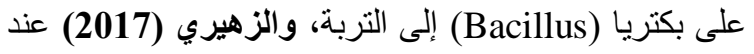

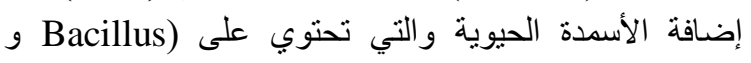
Azotobacter المطعمة على أصلين من الحمضيات.

في حين أظهرت النتائج تفوقاً معنوياً لمعاملة السماد

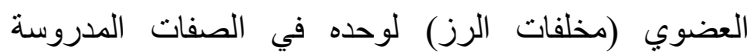
(محتوى التربة من النتروجين و الفسفور و البوتاسيوم الجاهز

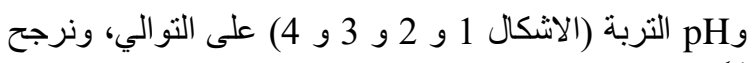

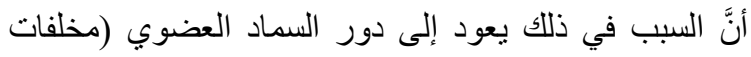
الرز) المضاف إلى التربة في زيادة جاهزية العناصر التئية الغذائية

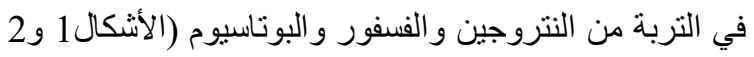

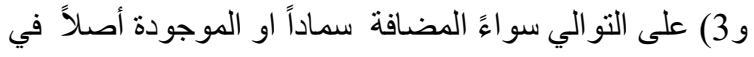

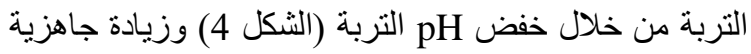

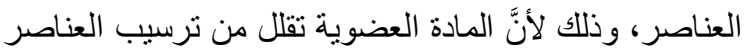
لاسيما الفسفور، إذ تعمل المادة العضوية على تلى تلغليف دقائق

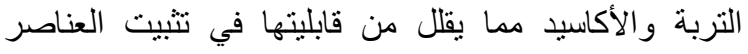

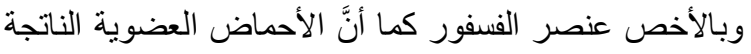

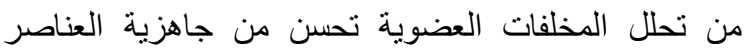

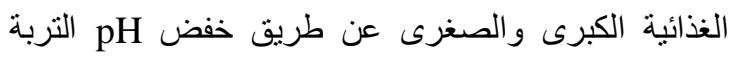

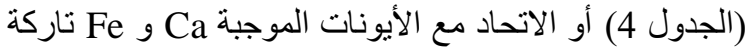

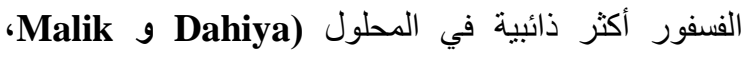

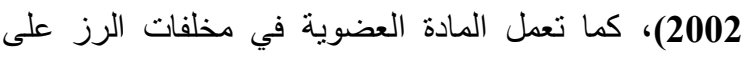

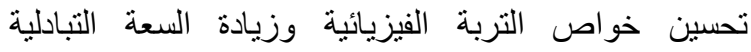
الكاتيونية وكنلك خفض pH التربة (الثكل 4) عن طريقانية تحلل المادة العضوية في السماد العضوي مكونةً العديد من لكن 
جدول 4. تأثير التاخل الثنائي والثلاثي للسماد الحيوي ومخلفات الرز والاب في درجة تفاعل

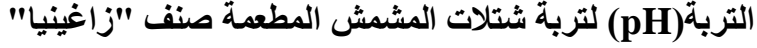

\begin{tabular}{|c|c|c|c|c|c|}
\hline \multirow{2}{*}{ 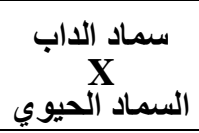 } & \multicolumn{3}{|c|}{ مخلفات الرز (كفم.شتلة_1) } & \multirow{2}{*}{ (غم.شتلة-1') } & \multirow{2}{*}{ (غم.شتلة_-1) } \\
\hline & 2 & 1 & صفر & & \\
\hline 7.36 أ ب & 7.33 ب & 7.33ب & 7.43 & صفر & \multirow{3}{*}{ صفر } \\
\hline 7.33 أ_ج & 7.33 ب & 7.33 ب & 7.33 & 1 & \\
\hline 7.32 أ ج & 7.23 ج د & I 7.43 & 7.30 ب ج & 2 & \\
\hline 7.30 ب ج & 7.23 ج د & 7.33 ب & 7.33 ب & صفر & \multirow{3}{*}{5} \\
\hline 7.36 أب & 7.33 ب & I 7.43 & 7.33 ب & 1 & \\
\hline 7.28 ج & 7.23 ج د & 7.20 & 17.43 & 2 & \\
\hline 7.30 ب ج & .7 .13 & 7.43 & ال & صفر & \multirow{3}{*}{10} \\
\hline 7.30 ب ج & 7.33 ب & 7.23 ج د & 7.33 & 1 & \\
\hline I 7.37 & 7.26 ب ج & I 7.43 & 17.43 & 2 & \\
\hline & ج 7.23 & 7.36 أ ب & 7.36 أب & صفر & \multirow{3}{*}{$\begin{array}{c}\text { السماد الحيوي } \\
\text { X } \\
\text { مخلفات الرز }\end{array}$} \\
\hline & 7.33 ب & 7.33 ب & 7.33 & 1 & \\
\hline & 7 7.24 & 7.35 أب & 7.38 & 2 & \\
\hline & 7.30 ب ج & 7.36 & 17.35 & صفر & \multirow{3}{*}{ سماد الداب } \\
\hline & 7.26 ج د & 7.32 أب & 17.36 & 5 & \\
\hline & 7.24 & 7.36 & I 7.36 & 10 & \\
\hline
\end{tabular}

حسين، مواهب مدحت (2016). نأثير السماد الكيمياوي

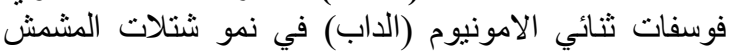

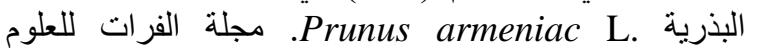

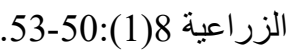

إبراهيم، عاطف محمد (1998). أنثجار الفاكهة. أساسيات

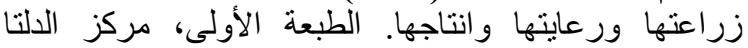
للطباعة، جمهورية مصر العربية.

الزبيدي، كريم معيان (2007). تأثثير إضافة السماد العضوي

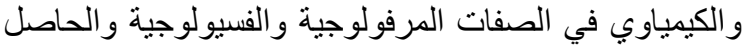

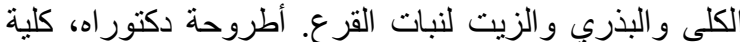

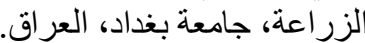

الزهيري، فارس فيصل عبد الغني (2017). استجابة شتلات السندي المشيري، المطعمة على أصلين من

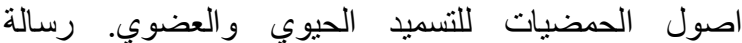
ماجستير، كلية الزر اعة، جامعة الكوفة، العراق.

شراقي، محمد محمود وعبد الهادي خضر وعلي سعد الدين

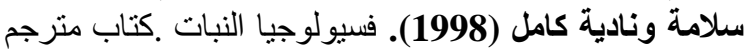

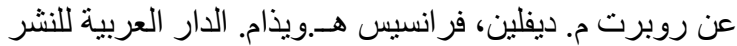
و التوزيع الطبعة الثانية ، جمهورية مصر النين العربية.

الطائي، زينب تركي إسماعيل وعلاء عيدان حسن وعباس

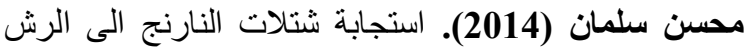

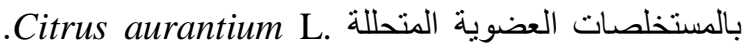
مجلة جامعة الكوفة للعلوم الزر اعية 6(2):1-14.

الأحول، كمال سالم (1994). تأثير مستويات النتروجين

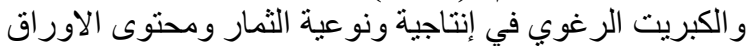

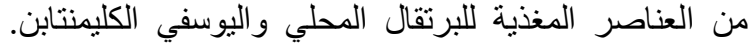
رسالة ماجستير ، كلية الزر اعة، جامعة لئية المداد.

البلدوي، محمد علي (2008). استخدام فطر المايكورايزا في التسميد البيولوجي. مجلة المرشد الإماراتية العدد 109:38 -

تاج الدين، منذر ماجد وحنون ناهي كاظم البركات (2016).

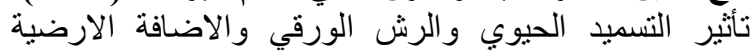

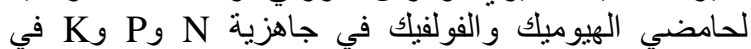
التربة. مجلة المثنى للعلوم الزر اعية 4(2):1-13.

جندية، حسن (2003). فسيولوجيا أنثجار الفاكهة. الدار العربية للنشر والتوزيع، مدينة النصر، مصر.

الحداد، زكريا عبد الرحمن (2003). الاستثمار في مجال لاعندال

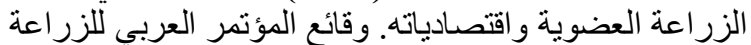

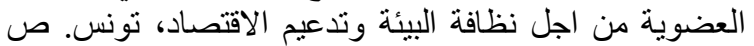
.270-261 
Micronutrients. (49-82). In Tandon, H.L.S. (eds). Methods of Analysis of Soils, Plants, Water and Fertilizers. Binng Printers L- 14, Lajpat Nagor New Delhi ,110024.

Blevin, D.G. (2001). Increasing the magnesium concentration of tall fescue leaves with phosphorus and boron fertilization. Plant Food Control. Missouri Agricultural Experiment station MU College of Agriculture, Food and natural Resources.

Dahiya, R. and Malik, R.S. (2002). Trash and green mulch effects on soil $\mathrm{N}$ and $\mathrm{P}$ availability. Part of Ph.D. thesis. CCS Haryana Agric. Univ., Hisar, India.

El-Komy, H.M. (2005). Coimmobilization of zospirillum lipoferm and bacillus megaterium for successful phosphorus and nitrogen nutrition of wheat plants. J. Food Technol. Biotechnol., 43(1):19-27.

Esitken, A.; Karlidag, H.; Ercisli, S.; Turan, M. and Sahin, F. (2003). The effect of spraying a growth promoting bacterium on the yield, growth and nutrient element composition of leaves of apricot (Prunus armeniaca L.cv. Hacihaliloglu). Aust. J. Agric. Rese., 54(4): 377-380

Esitken, A.; Pirlak, L.; Turan, M. and Sahin. F. (2006). Effects of floral and foliar application of plant growth promoting rhizobacteria (PGPR) on yield, growth and nutrition of sweet cherry. Sci. Hort., 110(4): 324-327.

Fawzi, M.I.F; Shahin, F.M.; Daood, E.A. and Kandil, E.A. (2010). Effect of organic and biofertilizers and magnesium sulphate on growth yield, chemical composition and fruit quality of "Le-Conte" pear trees. Nature \& Sci., $8(12): 273-280$.

Garcia, J.K.; Linan, J.; Sarmiento, R. and Troncoso, A. (1999). Effect of different N forms and concentrations on olive seedlings growth. Acta Hort., 474:323-327.

Hassan, P. and Azimi, D.J. (2012). Evaluation of out salt anti-stress material effects on minituber production of potato cultivars under in vivo condition. J. Food Agric. \& Inviromen., 10(1): 256-259.

Jackson, M.L. (1958). Soil Chemical Analysis. Prentis - Hall Inc. Englewood, Cliffs, N. J.
العباسي، غالب بهيو عبود وعلاء عيدان حسن ومسلم عبد علي الحسين (2015). استجابة ثلاثة أصول من العان الحمضيات للتسميد العضوي و الصخر الفوسفاتي. مجلة جامعة بابل للعلوم العنية الصرفة والنطبيقية 23(3):1206-1221.

العباسي، غالب بهيو عبود وفارس فيصل عبد الغني الزهيري

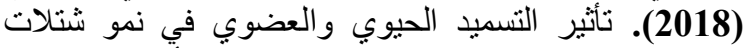
السندي Citrus grandis L. المطعة الكيرة على أُصول مختلفة. مجلة جامعة الكوفة للعلوم الزراعية 10(2):39-61 الكئ

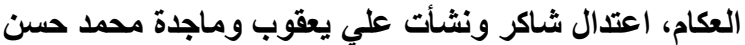

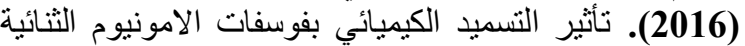
و الرش بالسماد الورقي GAP green في نمو شتلات فئلات

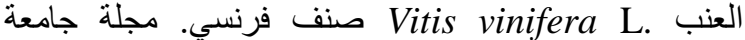
كربلاء العلمية 14(3)119-126.

علي، تهاني جواد محمد وثامر حميد خليل الصالحي وعلي

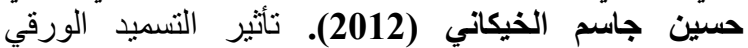

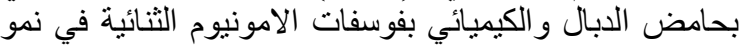
شتلات الزيتون صنف شتامي. مجلة الفرات للعلوم الزراعية فئية .17-1:(2)3

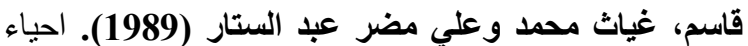

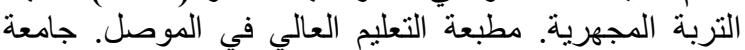
الموصل، جمهورية العراق.

محمد، عبد العظيم كاظم (1985). اساسيات فسيولوجيا النبات.

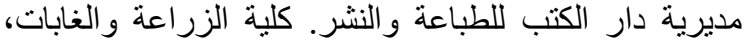

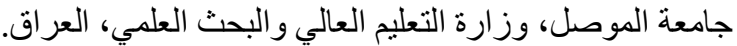
الموصلي، مظفر احمد (2018). الكامل في الاسمدة و التسميد. دار الكتب العلية، لبنان.

النعيمي، سعد الله نجم عبد الله (1984). مبادئ تغذية النبات (مترجم) .دار الكتب للطباعة و النشر. جامعة الموصل. وزارة

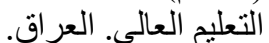

يوسف، يوسف حنا (1984). علم فاكهة المناطق المعتدلة (كتاب مترجم). مديرية دار الكتب للطباعة والنشر ، جامعة الناطية

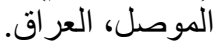

Abd ella, E.E.K. (2006). Effect of biofertilization on reducing chemical fertilizers, vegetative growth, nutritional status, yield and fruit quality of Arabi pomegranate trees. J. Agric. \& Env.Sci. 5(3):1-21.

Afzel, M. and Admas, W.A. (1992). Heterogenrity of soil mineral nitrogen in pasture grazed by cattle. Soil Sci. Soc. Amer. J., 56(4):1160-1166.

Barakat, M.R.; Yehia, T.A. and Sayed, B.M. (2012). Response of Newhall Naval Orange to Bio-Organic Fertilization under Newly Reclaimed Area Conditions I: Vegetative Growth and Nutritional Status. J. Hort. Sci. \& Ornamental Plants, 4(1): 18-25.

Bhargava, B.S. and Raghupathi, H.B. (1999). Analysis of Plant Materials for Macro and 
Scialabba, N.E. (2002). Organic Agriculture, Environmental and food Security. FAO-Rome.

Shaimaa, A.M. and Massoud, O.N. (2017). Impact of inoculation with mycorrhiza and azotobacter under different $\mathrm{N}$ and $\mathrm{P}$ rates on growth, nutrient status, yield and some soil characteristics of Washington Navel orange trees. Middle East J. Agric. Res., 6(3): 617-638.

Shekhar, C.; Bhadauria, S.; Kumar, P.; Lal, H.; Mondal, R. and Verma, D. (2006). Stress induced phosphate solubilization in bacteria isolated from alkaline soils. FEMS. Microbiology, 182: 291-296.

Siddiqui, Z.A. (2006). Biocontrol and biofertilizeration. A review Bioresource Technol. 69: 79-167.

Walpola, B.C. and Yoon, M.H. (2012). prospectus of phosphate solubilizing microorganisms and phosphorus availability in agricultural soil. African J. Advances in Agronomy 81: 97-168.

Zaghloul, R.A. (2002). Biofertilization and organic manuring efficiency on growth and yield of potato plants (Solanum tuberosum L.). Recent Technologies in Agriculture. Proceedings of the 2nd congress. Faculty of agriculture. Cairo University. 79-95.
Khalil, H.A. (2012). The potential of biofertilizers to improve vegetative growth, nutritional status, yield and fruit quality of Flame Seedless grapevines. American-Eurasian J. Agric. and Environ. Sci., 12 (9): 1122-1127.

Mario, H. E.; Regina, L.C. and Cereced, M.S. (2002). Emergence and survival of grasses inoculated with biofertilizors in a greenhouse study. Tecn. Pec. Mex., 42(3): 459-475.

Mostafa, M.F.M.; El-Baz, B.T.; Abd ElWahab, A.F. and Asmaa, S.M.O (2011). Using different sources of compost tea on grapes. J. Plant Production, Mansoura Univ., 2 (7): $935-947$.

Page, A.L.; Miller, R.H. and Keeny, D.R. (1982). Methods of soil Analysis part (2) 2nd(ed). Agronomy 9. Amer. Soc. Agron. Madison Wisconsin.

Punia, M.S. (2007). Wild apricot. national oil seeds and vegetable oils development board. Ministry of Agriculture, Govt. of India.

Sahain, M.F.M.; Abd El Motty, E.Z.; ElShiekh, M.H. and Hagagg, L.F. (2007). Effect of some biostimulant on growth and fruiting of Anna apple trees in newly reclaimed areas. Res. J. Agric. \& Biol. Sci., 3(5): 422-429. 